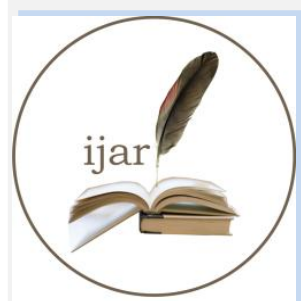

ISSN NO. 2320-5407

\section{Journal Homepage: - www.journalijar.com INTERNATIONAL JOURNAL OF ADVANCED RESEARCH (IJAR)}

Article DOI: $10.21474 / \mathrm{IJAR01/1424}$

DOI URL: http://dx.doi.org/10.21474/IJAR01/1424
INTERNATIONAL JOURNAL OF ADVANCED RESEARCH (JJAR)

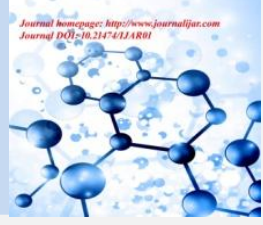

RESEARCH ARTICLE

\title{
COMPARISON BETWEEN LATERAL PARASAGITTAL INTERLAMINAR EPIDURAL AND TRANSFORAMINALCORTECOSTEROIDS INJECTION IN PATIENT WITH LOW BACK PAIN: SPREAD AND CLINICAL RESPONSE.
}

Mostafa Mohamed El Saied El Hamamsy MD., Ashraf Mohamed Yehia Hamed Heikal MD., Mohamed Awad Al Saeid Ahmed MD. And Mohamed Ahmed Shawky Mohamed M.sc.

\section{Manuscript Info}

Manuscript History

Received: 12 June 2016

Final Accepted: 19 July 2016

Published: August 2016

Key words:-

Lateral parasagittal, Transforaminal,

Ventral epidural spread, VAS

\section{Abstract}

Transforaminal and lateral parasagittal interlaminar epidural are considered techniques of epidural steroid injection for treating low back pain due to unilateral radiculopathy.

The aim of this study is comparing between the two techniques regarding ventral epidural spread and patient clinical response regarding VAS score.

We found that lateral parasagittal interlaminar was superior regarding ventral epidural spread with no differences regarding patient clinical response.

Copy Right, IJAR, 2016,. All rights reserved.

\section{Introduction:-}

Low back pain is disabling problem affects all people under age of $45 \cdot{ }^{[1]}$ Epidural injection of medications for management of low back pain and lower extremity pain was introduced in 1901 by Cathelin, Pasqier, Leri and Sicard ${ }^{[2]}$ Cathelin injected cocaine into the caudal route, ${ }^{[3]}$ while in 1952 Viner used Procaine, Ringer's solution and Saline ${ }^{[3]}$ The underlying mechanism of action of Epidurally administered Steroids, it has been shown that Corticosteroids has anti-inflammatory effect by inhibiting the synthesis of pro-inflammatory mediators In contrast, local anesthetics have been described to provide short-to-long term symptomatic relief by suppression of nociceptive discharge, the block of axonal transport of the sympathetic reflex arch and the block of sensitization. ${ }^{[4]}$ Lumbar midline interlaminar and transforaminal (TF) epidural steroid injections are treatments for low back pain with radiculopathy secondary to degenerative disk disease. ${ }^{[5,6]}$ Since pain generators are located anteriorly in the epidural space, ventral epidural spread is the logical target for placement of antiinflammatory medications. The potential advantages of transforaminal over interlaminar and caudal, include targeted delivery of a steroid to the site of pathology, presumably onto an inflamed nerve root. ${ }^{[7,8]}$ In this randomized, prospective, observational study, we compared contrast flow patterns in the epidural space using the parasagittal interlaminar (PIL) and transforaminal approaches with continual fluoroscopic guidance. ${ }^{[9]}$

\section{Materials and Methods:-}

- This study included 60 patients after departmental approval and informed consent, in Fayoum University hospitals.

- Subjects were randomly assigned to one of two groups: TF or PIL (30 in each).

- All procedures were performed using continual fluoroscopic guidance and $5 \mathrm{~mL}$ of contrast.

- Contrast spread was rated (primary outcome measure) by the interventionalist. Spread was scored 0-2, with 0 _ no anterior spread; 1 _ anterior spread, same level as needle insertion; and 2 _ anterior spread at $\geq 1$ segmental height. 


\section{Inclusion criteria:-}

- Patients will be chosen of both sexes

- Patients with low back pain and unilateral radiculopathy from herniated or degenerated discs.

Type of the study:- Comparative.

\section{The patients allocated into two groups each of 30 patients:-}

Group I. Lateral parasagittal interlaminar epidural approach group.

Group II: Transfominal epidural approach group.

\section{Exclusion criteria:-}

1. Patients with history of previous spinal surgery.

2. Patients with epidural steroids injection in the past year.

3. Allergy to drugs used.

4. Concurrent use of systemic steroid medications.

5. Opioid habituation.

6. Pregnancy.

\section{Parameters:-}

All measurements performed by a trained unblinded observer who will be involved in the clinical procedure, as described previously.

1. The degree of spread was quantified using a grading scale from 0 to 2 .

2. Anterior spread was considered present if the dye traveled to the level of the posterior longitudinal ligament or abutted the posterior aspect of the contiguous vertebral body(s) at the level of the needle insertion.

3. The percentage of patients demonstrating anterior epidural spread was reported in each group.

4. Fluoroscopy time was measured consecutively for all scout films, at each needle adjustment according to the protocol, and for the contrast injection phase. Fluoroscopy use was real-time and continuous (i.e., without interruption) during the contrast injection phase.

5. Pain relief using visual analog scale score (VAS) at 2 week , 1 and 3months were evaluated.

\section{Anesthetic management:-}

All patients were positioned prone, and standard ASA monitors were applied. The corresponding authors who were supervising Pain Management Fellows performed all injections. Fluoroscopic bi-planar imaging was used, with nonionic contrast (total volume $\_5.0 \mathrm{~mL}$ ) in anterior-posterior (AP) and lateral views. Fluoroscopy time was measured consecutively for all scout films, at each needle adjustment according to the protocol, and for the contrast injection phase. Fluoroscopy use was real-time and continuous (i.e., without interruption) during the contrast injection phase, with all personnel, except for the person performing the actual injection, standing more than $6 \mathrm{ft}$ from the radiation source.

For the PIL approach, a 20-gauge 3.5 in.Tuohy-type epidural needle was introduced at the level of demonstrated disk pathology by imaging, at the point corresponding to the lateralmost part of the interlaminar opening at its midlevel as indicated by the direct AP projection on fluoroscopy (no oblique or cephalo-caudad tilt used). The needle was advanced directly perpendicular to the skin in a posterior to anterior direction, with the use of the lossof-resistance to air technique in order to identify the epidural space. The parasagittal orientation of the needle was maintained throughout the procedure. Once the loss-of-resistance was obtained, contrast media, $5 \mathrm{~mL}$ (Iohexol-180, Amersham Health, Oslo, Norway) was injected using real-time, continuous fluoroscopy for the entire volume of 5 $\mathrm{mL}$ of injectate, and images were obtained in the lateral and AP projections . The use of the real-time and continuous imaging was to verify that no contrast attained intravascular, subarachnoid, subdural, or intradiscal spread.

Next, the antiinflammatory corticosteroid, methylprednisolone acetate, $80 \mathrm{mg}$, along with $1 \mathrm{~mL}$ of normal saline and $1 \mathrm{~mL}$ of lidocaine 1\%, was injected into the epidural space (total volume; $4 \mathrm{~mL}$ ). The saline was added to dilute polyethylene glycol $4000(28.6 \mathrm{mg} / \mathrm{mL})$, the vehicle added during manufacture of methylprednisolone that has been implicated to be associated with arachnoiditis.

For the TF approach, a 22-gauge 3.5 in. Whitacre pencil point needle with the tip slightly curved was introduced at the appropriately documented level of disk pathology using first an AP and, subsequently, an oblique orientation of 
the fluoroscopy $\mathrm{C}$-arm. Once the superior pars interarticularis was identified, the C-arm was oriented obliquely 15 degrees in the caudocephalad direction. The needle was advanced towards the tip of the pars until that structure was contacted, and the needle tip was then advanced in a slightly cephalad direction. The needle was advanced until the needle tip was at the posterior and superior aspect of the intervertebral neural foramen as seen in the lateral projection, and in line with the pedicle on AP view. After incremental injection of the contrast media, the same volume and dose of corticosteroid as above for the PIL technique was injected with continual intermittent aspiration. On the lateral projection, the patterns of contrast spread were documented as "anterior" or "posterior" and the degree of spread was quantified using a grading scale from 0 to 2 . Anterior spread was considered present if the dye traveled to the level of the posterior longitudinal ligament or abutted the posterior aspect of the contiguous vertebral body at the level of the needle insertion.

The percentage of patients demonstrating anterior epidural spread was reported in each group. Also, the total fluoroscopy time and pain relief using visual analog scale score (VAS) at 2 week and 1 month were evaluated.

\section{Results:-}

Table 1:- Sex distribution in group I and group II

\begin{tabular}{|c|c|c|c|c|}
\hline \multicolumn{2}{|c|}{ Sex } & \multicolumn{2}{|c|}{ Groups } & \multirow[t]{2}{*}{ Total } \\
\hline & & Group IPIL $(\mathrm{n}=30)$ & Group IITF $(\mathrm{n}=30)$ & \\
\hline \multirow[t]{2}{*}{ Male } & $\mathrm{N}$ & 18 & 18 & 36 \\
\hline & $\%$ & 60 & 60 & 60 \\
\hline \multirow[t]{2}{*}{ Female } & $\mathrm{N}$ & 12 & 12 & 24 \\
\hline & $\%$ & 40 & 40 & 40 \\
\hline \multirow[t]{2}{*}{ Total } & $\mathrm{N}$ & 30 & 30 & 60 \\
\hline & $\%$ & 100.00 & 100.00 & 100.00 \\
\hline
\end{tabular}

PIL= Parasagittal Interlaminar Injection

$\mathrm{TF}=$ Transforaminal Injection

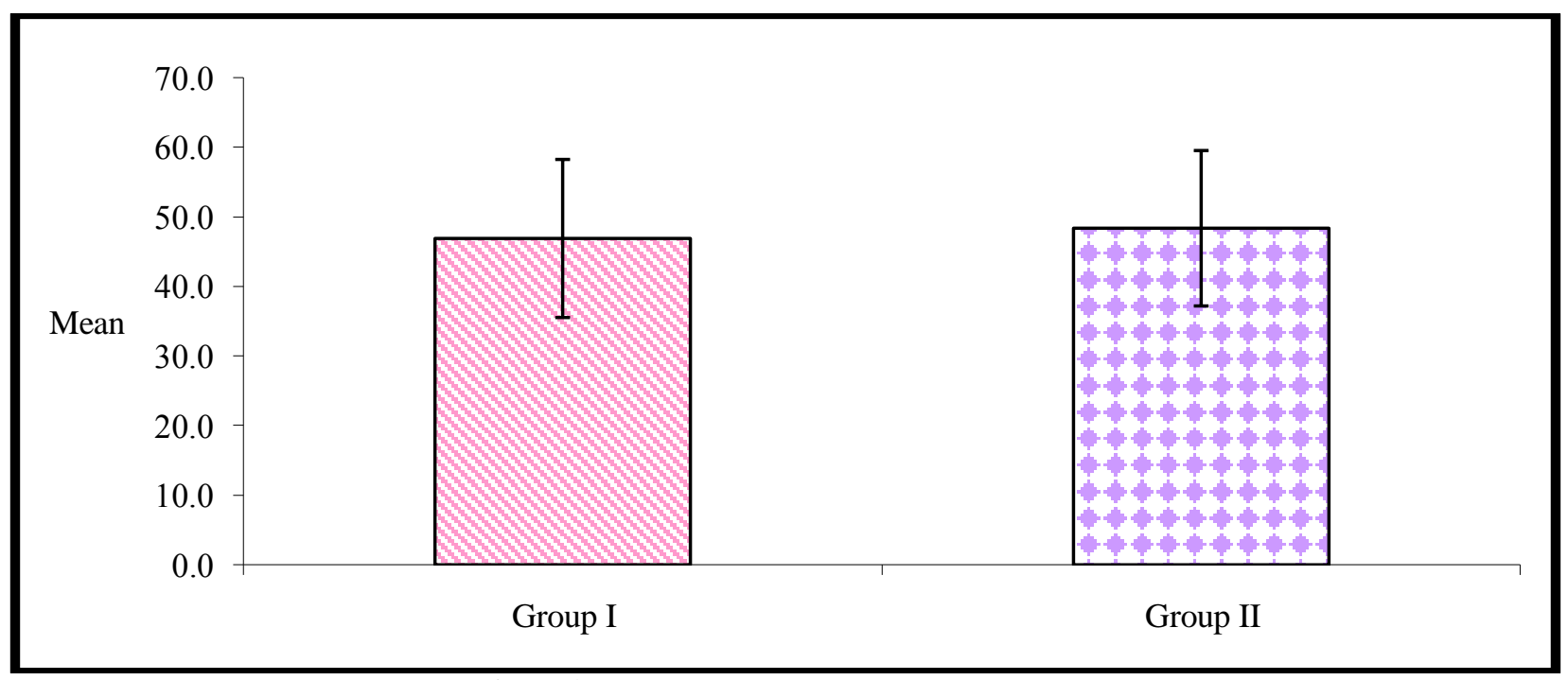

Figure1:- Age distribution in the study groups.

The spread of contrast in patients between TF and PIL groups was as follows: all patients (30 of 30) (100\%) in the PIL group and (22 of 30)(73.33\%) patients in the TF group demonstrated anterior epidural spread with statistically significant difference between the two group. P-value (0.002).(table 2), (figure 2) 
Table 2:- Anterior spread in group I and group II.

\begin{tabular}{|c|c|c|c|c|}
\hline \multicolumn{2}{|c|}{ Anterior spread } & \multicolumn{2}{|c|}{ Groups } & \multirow{3}{*}{$\begin{array}{c}\text { Total } \\
52\end{array}$} \\
\hline & & Group IPIL $(\mathrm{n}=30)$ & Group IITF $(n=30)$ & \\
\hline \multirow[t]{2}{*}{ Yes } & $\mathrm{N}$ & 30 & 22 & \\
\hline & $\%$ & 100 & 73.33 & 86.67 \\
\hline \multirow[t]{2}{*}{ No } & $\mathrm{N}$ & $\overline{0}$ & 8 & 8 \\
\hline & $\%$ & 0.00 & 26.67 & 13.33 \\
\hline \multirow[t]{2}{*}{ Total } & $\mathrm{N}$ & 30 & 30 & 60 \\
\hline & $\%$ & 100.00 & 100.00 & 100.00 \\
\hline \multirow[t]{2}{*}{ Chi-square } & $\mathrm{X}^{2}$ & \multicolumn{3}{|c|}{9.231} \\
\hline & P-value & & $0.002 \mathrm{~S}$ & \\
\hline
\end{tabular}

$\mathrm{S}=$ Significant

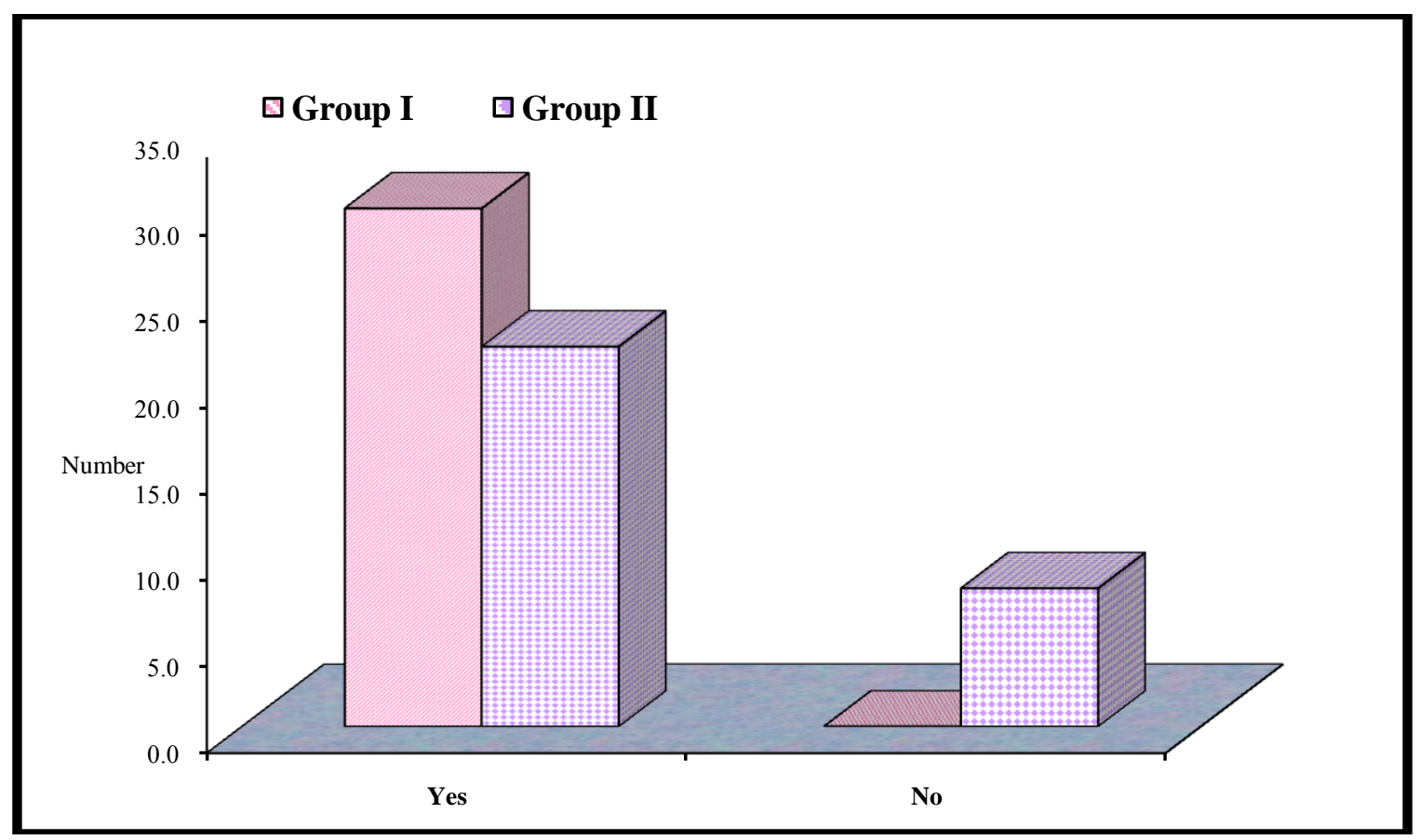

Figure 2:- Anterior spread in the two groups.

The mean spread grade was $(1.90 \pm 0.31)$ in the PIL group and $(1.03 \pm 0.77)$ in the TF group ( P 0.000) with statistically significant difference between the two groups. (Table 3, Figure 3)

Table 3:- Spread Scale in the study groups.

\begin{tabular}{|c|r|r|l|r|l|l|c|c|}
\hline \multirow{2}{*}{ Groups } & \multicolumn{4}{|c|}{ Spread Scale } & \multicolumn{2}{c|}{ T-test } \\
\cline { 2 - 7 } & \multicolumn{2}{|c|}{ Range } & Mean & \pm & SD & t & P-value \\
\hline Group I (PIL) $\mathrm{n}=30$ & 1 & - & 2 & 1.90 & \pm & 0.31 & 5.76 & $0.000(\mathrm{~S})$ \\
\hline Group II (TF) $\mathrm{n}=30$ & 0 & - & 2 & 1.03 & \pm & 0.77 & & \\
\hline
\end{tabular}

$\mathrm{t}=$ student's t-test 


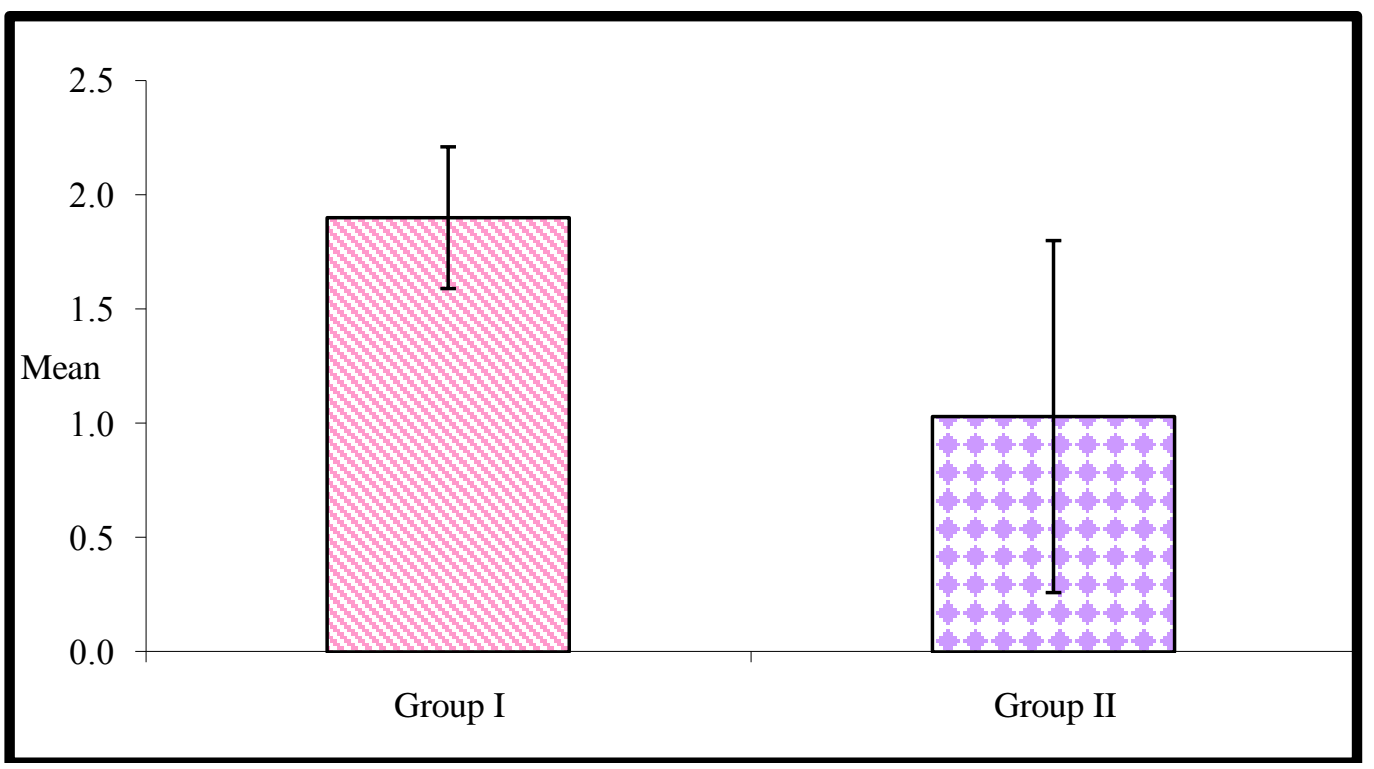

Figure 3:- Spread Scale in the study groups.

Mean fluoroscopy time was ( $28.13 \pm 2.60 \mathrm{~s})$ in the PIL group and $(46.40 \pm 6.31 \mathrm{~s})$ in the TF group ( P- value 0.000) with statistically significant between the two groups. (table 4), (figure 4)

Table 4:- Mean Fluoroscopy Time in the study groups.

\begin{tabular}{|c|c|c|c|c|c|c|c|}
\hline \multirow[t]{2}{*}{ Groups } & \multicolumn{5}{|c|}{ Fluoroscopy time (sec) } & \multicolumn{2}{|c|}{ T-test } \\
\hline & \multicolumn{2}{|c|}{ Range } & Mean & \pm & SD & \multirow{3}{*}{$\begin{array}{c}\mathrm{t} \\
14.671\end{array}$} & P-value \\
\hline Group I & 22 & 33 & 28.13 & \pm & 2.60 & & \multirow{2}{*}{$0.000(\mathrm{~S})$} \\
\hline Group II & 35 & 57 & 46.40 & \pm & 6.31 & & \\
\hline
\end{tabular}

$\mathrm{t}=$ student's t-test

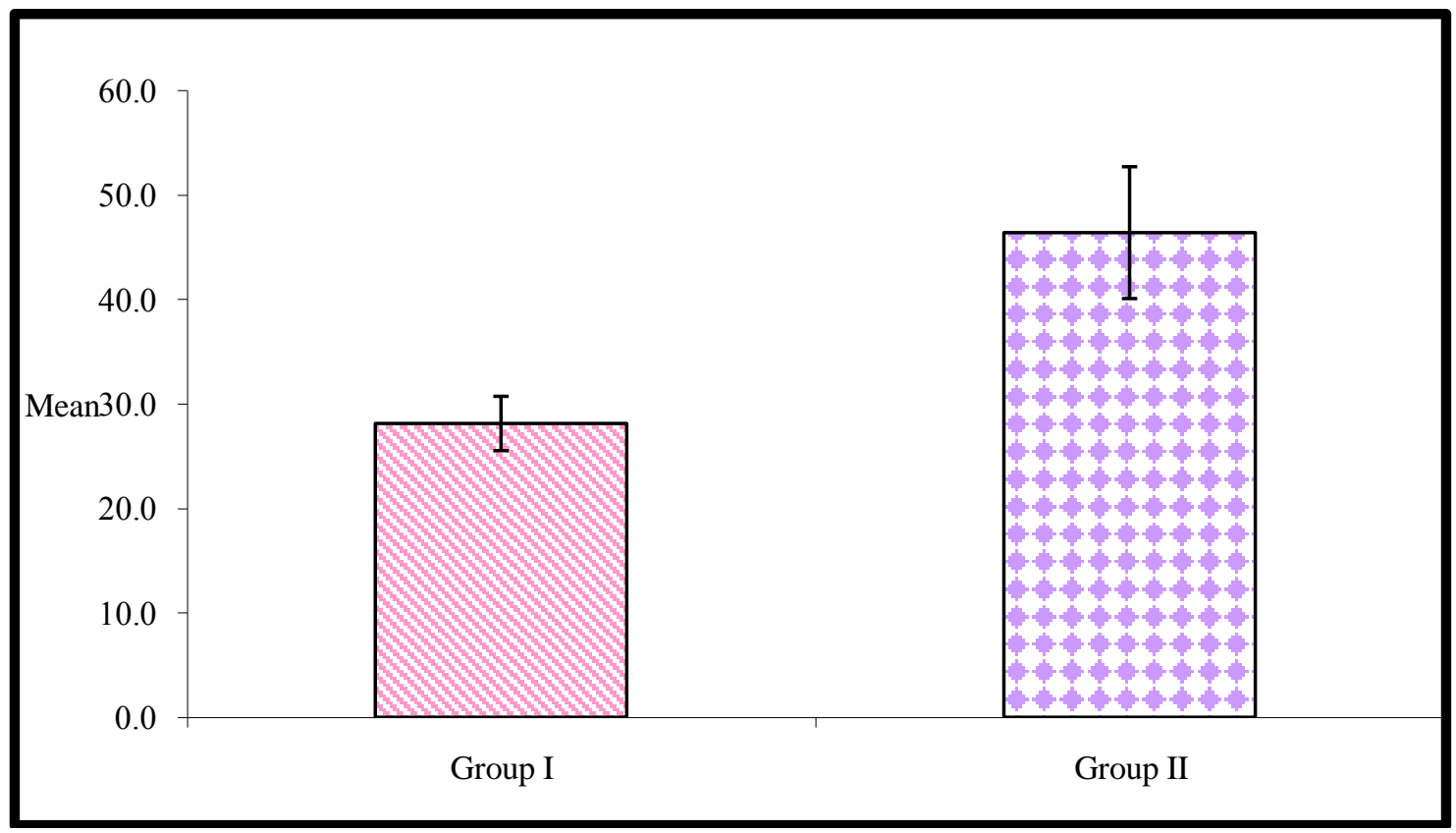

Figure 4:- Mean Fluoroscopy Time distribution in the study groups.

These data are represented in (Table 5 and Figure 5) and show VAS across time. There were no differences from control within either group. The aggregate pain VAS scores were less at all times compared with baseline. There 
was no statistically significant difference regarding VAS scores between the study groups.

There were no observed dural punctures in either group, no subdural or intrathecal injections, and no intrathecal or intradiscal injections. No patient in either group sustained any infectious complications, postdural puncture headache, persistent paresthesias, systemic steroid reactions, skin lesions, or any adverse reaction to contrast media or adjuvant medications.

Table5:- Comparison of the degree of VAS before and after injection between the study two groups.

\begin{tabular}{|l|c|c|c|c|c|c|c|}
\hline \multirow{2}{*}{ VAS } & \multicolumn{2}{|c|}{ Group 1 (PIL) } & \multicolumn{2}{c|}{ Group 2 (TF) } & \multirow{2}{*}{ T-value } & P-value & \multirow{2}{*}{ Sig. } \\
\cline { 2 - 5 } & Mean & SD & Mean & SD & & & \\
\hline Base Line & 8.00 & 1.02 & 8.00 & 1.08 & 0.000 & 1.000 & NS \\
\hline After 2 Weeks & 4.30 & 1.12 & 4.40 & 0.81 & 0.396 & 0.694 & NS \\
\hline After 1 Month & 5.37 & 0.85 & 5.30 & 0.70 & 0.331 & 0.742 & NS \\
\hline After 3 Months & 4.70 & 0.65 & 4.63 & 0.99 & 0.306 & 0.761 & NS \\
\hline
\end{tabular}

$\mathrm{SD}=$ standard deviation. $\mathrm{NS}=$ not significant.

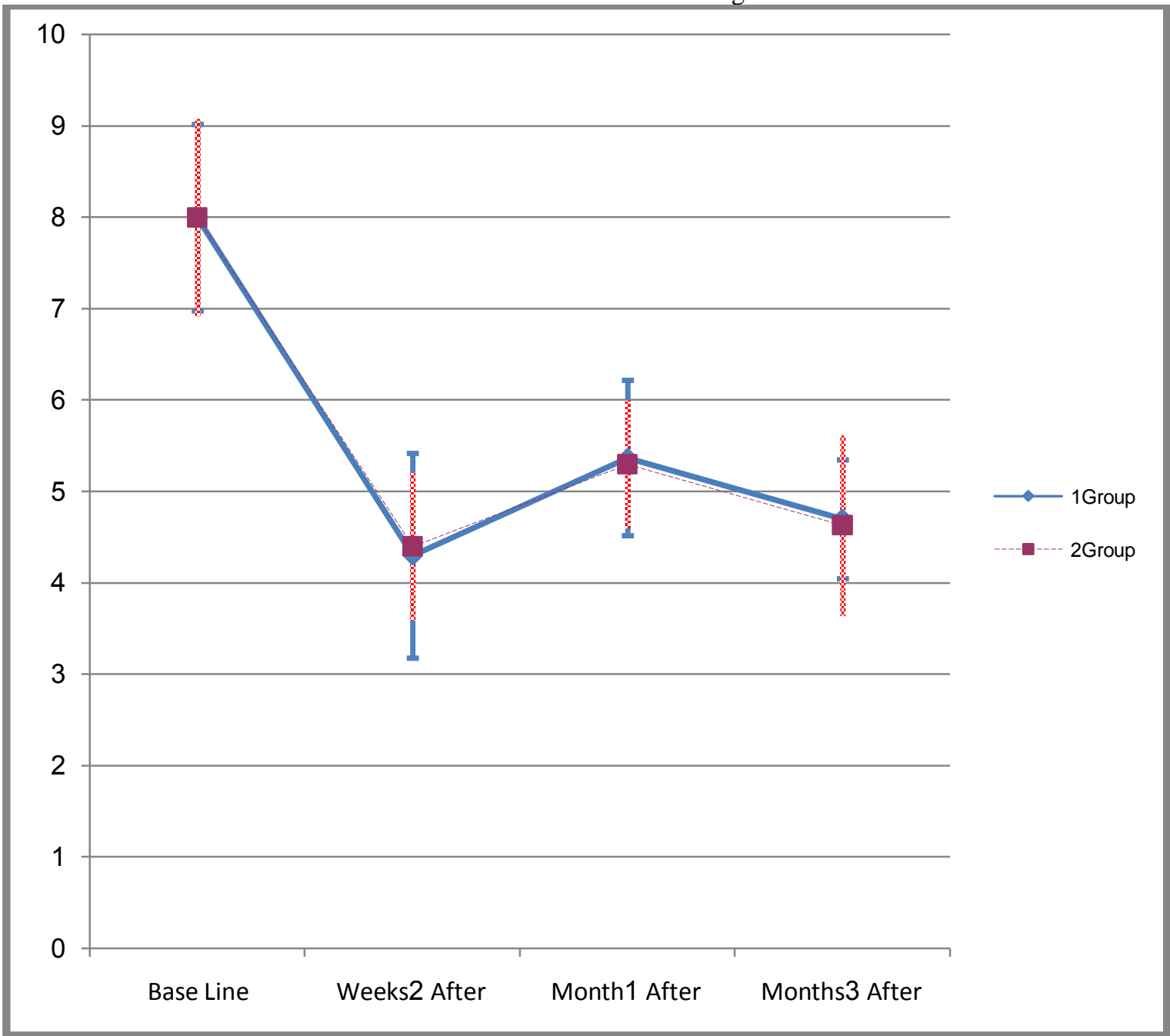

Figure5:- VAS.

\section{Discussion:-}

This study revealed comparable health benefits with both the PIL and TF approach regarding effective pain relief for managing patient with chronic low back pain with unilateral radicular pain. Improvement was observed with both approaches with no significant differences regarding pain intensity (VAS) between the two techniques. 
Among various approaches of epidural steroids injection used to treat low back pain such as midline interlaminar ,TF and caudal epidural injection Previous studies found that TF is more superior than others regarding pain response and depositing drug at pathology site (William E. Ackerman et al). ${ }^{[96]}$

TF is considered as target specific and more effective as compared to IL in the past. ${ }^{[06,97,98,99]}$ This may be due to blind administration or fluoroscopic guidance needle placement in the dorsal space of IL technique leading to limited ventral epidural spread of steroid $\left(28 \%-47 \%\right.$ only). ${ }^{[13,100]}$ Studies have suggested the superiority of TF ESIs for both short and long-term outcomes. ${ }^{[96,97,98,99]}$

A retrospective study by Schaufele et al ${ }^{[98]}$, assessing pain improvement and surgical rates between IL (midline approach) and TF injection over 18 months, reported TF ESI's superiority in short-term pain improvement and longterm surgical interventions.

However, recent studies ${ }^{[101,102,103,104]}$ and systematic reviews ${ }^{[105,106]}$ showed an equivalence of IL and TF injections. Rados et al ${ }^{[102]}$, while comparing TF and IL (paramedian approach) approaches in patients with chronic unilateral radiculopathy, demonstrated significant functional and pain improvement with both approaches. Gharibo et al ${ }^{[103]}$, while comparing IL (midline approach) and TF techniques in patients with subacute unilateral radiculopathy, reported comparable significant improvements in pain, function, and depression. Although effective, TF injections sometimes lead to complications including spinal cord injury and permanent paralysis. ${ }^{[15,16,17]}$

In an effort to provide a suitable and reliable alternative to the TF approach, we studied the parasagittal interlaminar (PIL) epidural approach. Lately, good ventral epidural spread is reported when the needle was placed in the lateral most part of the epidural space. ${ }^{[12,107]}$ Candido et al ${ }^{[12]}$ demonstrated $100 \%$ ventral epidural spread with the PIL approach and $75 \%$ spread with the TF approach. Choi and Barbella ${ }^{[107]}$ reported ventral epidural spread in all patients using the LIVE (lumbar interlaminar ventral epidural) approach of injection. However, these studies investigated contrast spread as the primary outcome. The clinical significance was either not elucidated ${ }^{[107]}$ or was limited by the observational uncontrolled nature. ${ }^{[12]}$

Studies were done evaluating clinical significance of PIL with MIL (midline interlaminar) approach as Ghai B et al ${ }^{[108]}$ reported that PIL was superior to the MIL approach. The PIL approach provided more patients with effective pain relief (68.4\% versus $16.7 \%$ at 6 months), better ventral epidural spread (89.7\% versus $31.7 \%$ in MIL), better functional improvement, and less number of injections. ${ }^{[108]}$ this agreed by Weil L et al ${ }^{[100]}$ who prove that contrast spread in ventral epidural space is reported to be only $28 \%$ to $47 \%$ in IL epidural injection.

The objective of this study was to compare between PIL group and TF group regarding clinical response and ventral spread under fluoroscopy.

It was found that PIL group is more superior than TF with statistical significance regarding ventral spread under fluoroscopy ( all patients (30 of 30) (100\%) in the PIL group and (22 of 30)(73.33\%) patients in the TF group demonstrated anterior epidural spread with statistically significant difference between the two group. P-value (0.002) as proved by Kenneth D. Candido et al. ${ }^{[12]}$ who said that ventral epidural spread in PIL group was $100 \%$ and $75 \%$ in TF group. while BabitaGhai et al ${ }^{[109]}$ proved that ventral epidural spread was comparable, $89.6 \%(52$ of 58 injections) in the TF group as compared to $91.6 \%$ (55 of 60 injections) in the PIL group ( $\mathrm{P}=0.64$ ) with no statistically difference between the two study group regarding ventral epidural spread and prove also that the incidence of perineural spread was statistically significant towards TF group. ${ }^{[109]}$

Fluoroscopy time was less in PIL group than TF group which mean less exposure to radiation hazards for interventionist and for patient. This was agreed by Kenneth D. Candido et al ${ }^{[12]}$ unlike BabitaGhai et al ${ }^{[109]}$ who said that fluoroscopy time between the two groups was comparable with $\mathrm{p}$ value $=0.25$

The difference in fluoroscopy time between the two techniques (PIL,TF) might be due to ease technique of PIL. the differences in results of fluoroscopy time between our study and other studies like BabitaGhai et al ${ }^{[109]}$ might be due to differences between interventionists.

Regarding VAS in this study there was reduction of pain in follow up compared to baseline but there was no 
difference between the two study groups. so both techniques considered equal in clinical response of pain reduction. this was agreed by Kenneth D. Candido et al. ${ }^{[12]}$

Schaufele et al ${ }^{[98]}$ found no difference in pain scores post injection between TF and IL approaches. However, the authors claimed a statistically significant superiority of TF for pain relief during a follow-up at up to 12 months. This conclusion is limited by repeated and uncontrolled use of additional epidural steroid injections and surgical interventions at undefined intervals during that 12 month period.

Ghai B et al ${ }^{[108]}$ found also that there is reduction of pain scores regarding baseline for both techniques achieving effective pain relief and functional improvement over 12 months. So this study agreed with all previous studies ${ }^{[12,98,108]}$ regarding the equality in clinical response as measured by (VAS). Kolsi et al ${ }^{[110]}$ proved that there is no difference regarding clinical response up to 4 weeks.Rados et al ${ }^{[102]}$ proved also that there is no difference in clinical response but up to 6 months. Others like William E. Ackerman et al ${ }^{[96]}$, Gharibo et al ${ }^{[103]}$, Thomas et al ${ }^{[111]}$ proved that TF approach has better clinical response than IL (midline approach).

Although there were no reports of permanent neurological sequelae found in that review, we question the need to perform TF injections when the PIL approach would allow to drive medication ventrally in the epidural space towards the interface of the exiting nerve root (i.e., the target) and the disk pathology (i.e., the etiology of the problem).with the same clinical outcomes and also less radiation exposure.

\section{Limitations:-}

Limitations included lack of documentation of adjuvant therapies like individual patient exercise routines and analgesic drug therapy. Other limitations are the utilization of a high volume contrast and a high volume mixture of methylprednisolone and sodium chloride solution. We used total of $5 \mathrm{~mL}$ of contrast which was equal to the volume of the drug used for injection. This amount of contrast and drug is within the range of volume used by previous investigators. ${ }^{[12,104]}$ Also, saline was added to dilute polyethylene glycol $4000(28.6 \mathrm{mg} / \mathrm{mL})$, the vehicle added during the manufacture of methylprednisolone that has been implicated to be associated with arachnoiditis. ${ }^{[12]}$

Since all procedures were performed by a single interventionialist, generalization of these results performed by other less or more experienced interventionialists remains yet to be established. Wider implications of this trial can only be extrapolated by conducting a clinic based study with the interventions performed by interventionists with different ranges of experience. The challenges in the implementation of these findings in clinical services are well appreciated and that our results might not be generalized to non-specialized health care settings or non-specific LBP patients.

additional treatment decisions were made on a case-to-case basis, limiting our ability to make outcome conclusions in many cases as to the efficacy of one technique over another. Further prospective large-scale multicenter outcome studies are needed to convincingly prove the efficacy and safety of the lateral PIL approach to the anterior epidural space versus TF injections.

\section{Conclussion:-}

Regarding epidural steroids injection with two comparable approaches either TF or PIL, We found that both techniques had the same clinical outcomes regarding pain improvement but PIL technique is considered a good ,safe and ease alternative to TF with less risk to hazardous complications of TF.

\section{References:-}

1. Bogduk N. Clinical Anatomy of the Lumbar Spine and Sacrum. New York, Churchill Livingstone 1997; 127:144.

2. Bentley A. Ogoke. Caudal Epidural Steroid Injections. Pain Physician, Volume 3, Number 3 2000: 305-312.

3. Jason S. Lipetz, SarjooBhagia, Thomas J. Dicarlo. Seated Transforaminal Injection Approach in Severe Lumbar Stenosis. Pain Physician, Volume 5, Number 2 2002: 206-209.

4. Pasqualucci A, Varrassi G, Braschi A, et al. Epidural local anesthetic plus corticosteroid for the treatment of cervical brachial radicular pain, Single injection verus continuous infusion. Clin J Pain 2007; 23: 551-557.

5. Benyamin RM, Singh V, Parr AT. Systematic review of the effectiveness of cervical epidurals in the management of chronic neck pain. Pain Physician 2010;12:137-57. 
6. Hayes, Inc. Medical technology directory. Epidural steroid injections for low back pain and sciatica. Lansdale, PA: Hayes, Inc. January 30,2013.

7. LaxmaiahManchikanti, Ricardo M. Buenaventura, Kavita N., et al. Effectiveness of therapeutic lumbar transforaminal epidural steroid injections in managing lumbar spinal pain. Pain Physician 2012;15 :E199-245.

8. Buenaventura RM, Datta S, Abdi S, Smith HS. Systematic review of therapeutic lumbar transforaminal epidural steroid injections. Pain Physician 2009; 12:233-251.

9. Kenneth D. Candido, Meda S. Raghavendra, MariadasChinthagada, SorayaBadiee, Donald W. Trepashko. A prospective evaluation of iodinated contrast flow patterns with fluoroscopically guided lumbar epidural steroid injections: the lateral parasagittal interlaminar epidural approach versus the transforaminal epidural Approach.Anesthesia\&Analgesia 2008;106:638-644.

10. William E. Ackerman, Mahmood Ahmad. The Efficacy of Lumbar Epidural Steroid Injections in Patients with Lumbar Disc Herniations. ANESTHESIA \&ANALGESIA. Vol. 104 May 2007;1217-1222.

11. Buenaventura RM, Datta S, Abdi S, Smith HS. Systematic review of therapeutic lumbar transforaminal epidural steroid injections. Pain Physician 2009;12:233-251.

12. Schaufele MK, Hatch L, Jones W. Interlaminar versus transforaminal epidural injections for the treatment of symptomatic lumbar intervertebral disc herniations. Pain Physician 2006; 9:361-366.

13. Parr AT, Diwan S, Abdi S. Lumbar interlaminar epidural injections in managing chronic low back and lower extremity pain: a systematic review. Pain Physician 2009; 12:163-188.

14. Weil L, Frauwirth NH, Amirdelfan K, Grant D, Rosenberg JA. Fluoroscopic analysis of lumbar epidural contrast spread after lumbar interlaminar injection. Arch Phys Med Rehabil 2008; 89:413-416.

15. Manchikanti L, Singh V, Falco FJ, Cash KA, Pampati V. Evaluation of the effectiveness of lumbar interlaminar epidural injections in managing chronic pain of lumbar disc herniation or radiculitis: A randomized, doubleblind, controlled trial. Pain Physician 2010; 13:343-355.

16. Rados I, Sakic K, Fingler M, Kapural L. Efficacy of interlaminarvstransforaminal epidural steroid injection for the treatment of chronic unilateral radicular pain: Prospective, randomized study. Pain Med 2011: 12:13161321.

17. Gharibo CG, Varlotta GP, Rhame EE, Liu EC, Bendo JA, Perloff MD. Interlaminar versus transforaminal epidural steroids for the treatment of subacute lumbar radicular pain: A randomized, blinded, prospective outcome study. Pain Physician 2011; 14:499-511.

18. Furman MB, Kothari G, Parikh T, Anderson JG, Khawaja A. Efficacy of fluoroscopically guided, contrastenhanced lumbosacral interlaminar epidural steroid injections: A pilot study. Pain Med 2010; 11:1328-1334.

19. Benyamin RM, Wang VC, Vallejo R, Singh V, Helm II S. A systematic evaluation of thoracic interlaminar epidural injections. Pain Physician 2012;15:E497-E514.

20. Atluri S, Glaser SE, Shah RV, Sudarshan G. Needle position analysis in cases of paralysis from transforaminal epidurals: Consider alternative approaches to traditional technique. Pain Physician 2013;16:321-334.

21. Huntoon MA, Martin DP. Paralysis after transforaminal epidural injection and previous spine surgery. A case report. RegAnesth Pain Med 2004;29:494-495.

22. Karaman H, Kavak GO, Tüfek A, Yldrm ZB. The complications of transforaminal lumbar epidural steroid injections. Spine (Phila Pa 1976) 2011; 36:E819-E824.

23. Epstein NE. The risks of epidural and transforaminal steroid injections in the spine: Commentary and a comprehensive review of the liberature. SurgNeurolInt 2013;4:S74-93.

24. Choi YK, Barbella JD. Evaluation of epidurographic contrast patterns with fluoroscopic-guided lumbar interlaminar ventral epidural injection. Pain Pract 2009; 9:275-281.

25. Ghai B, Vadaje KS, Wig J, Dhillon MS. Lateral parasagittal versus midline interlaminar lumbar epidural steroid injection for management of low back pain with lumbosacral radicular pain: A double-blind, randomized study. AnesthAnalg 2013; 117:219-227.

26. BabitaGhai, DipikaBansal and et al. Transforaminal Versus Parasagittal Interlaminar Epidural Steroid Injection in Low Back Pain with Radicular Pain: A Randomized, Double-Blind, Active-Control Trial. Pain Physician 2014; 17:277-290.

27. Kolsi I, Delecrin J, Berthelot J, et al. Efficacy of nerve root versus interspinous injections of glucocorticoids in the treatment of disk-related sciatica. A pilot, prospective, randomized, double-blind study. Joint Bone Spine 2000;67:113 Y118.

28. Thomas E, Cyteval C, Abiad L, et al. Efficacy of transforaminal versus interspinous corticosteroid injection in discalradiculalgiaa prospective, randomized, double-blind study. ClinRheumatol 2003;22:299 Y 304. 